\title{
Global disability burden and its predictors among adult Nigerians living with Type- 2 diabetes
}

\author{
Olufemi O. Oyewole ${ }^{1}$, Olatunde Odusan ${ }^{2}$ and Ayotunde O. Ale ${ }^{2}$
}

Ghana Med J 2019; 53(2): 135-141 doi: http://dx.doi.org/10.4314/gmj.v53i2.8

\author{
${ }^{1}$ Physiotherapy Department, Olabisi Onabanjo University Teaching Hospital, Nigeria \\ ${ }^{2}$ Medicine Department, Olabisi Onabanjo University Teaching Hospital, Nigeria
}

Corresponding author: Olufemi O. Oyewole

E-mail: oyewoleye@yahoo.co.uk, oyewoleye@gmail.com

Conflict of interest: None declared

\section{SUMMARY}

Background: Type 2 diabetes mellitus (T2DM) is a public health issue associated with a high prevalence of disability. Studies on disability profile in terms of reduction in body structure and function, personal activities and societal participation, defined as 'global disability', are scarce among people living with T2DM in Nigeria.

Objectives: To assess the prevalence of global disability and its predictors among Nigerian living with T2DM.

Methods: A cross-sectional analysis of 162 patients diagnosed with T2DM and attending a tertiary health facility was performed for global disability measure and function. Their clinical and socio-demographic data were obtained. Poisson regression analysis was applied to assess the predicting factors of disability.

Results: A mean global disability score of 22.1 was reported among the participants, varying from moderate to high in each item. About $25.0 \%$ had mild disability, while $60.5 \%$ reported moderate to severe disability. Elevated glycosylated haemoglobin, fasting blood glucose, systolic blood pressure, age, disease duration and marital status predicted disability. A unit increase in $\mathrm{HbA1c}$, systolic blood pressure and 1 month increase in DM duration had more disability reported estimates [1.062 (CI=1.050-1.075), $1.005(\mathrm{CI}=1.002-1.007)$ and $1.001(\mathrm{CI}=1.000-1.002)$ times, respectively]. Married participants were $1.13(\mathrm{CI}=1.02-1.23)$ times more likely to be disabled than unmarried.

Conclusions: There is mild to moderate burden and risk of global disability among Nigerian living with T2DM. Age, DM duration, marital status, fasting blood glucose, glycosylated haemoglobin and systolic hypertension significantly predicted disability.

Keywords: global disability; type 2 diabetes; predicting factors; Nigeria Funding: None declared

\section{INTRODUCTION}

Type-2 diabetes mellitus (T2DM) is a global public health issue with increased prevalence affecting about 415 million people $(8.8 \%$ of adults aged $20-79$ years in 2015 ) of which $75.0 \%$ live in low- and middle-income countries. ${ }^{1}$ If this trend continues, about 642 million people or one in 10 adults will have T2DM by $2040 .{ }^{1}$ In Nigeria, there is increasing burden of T2DM; many persons are currently undiagnosed with few of the known cases on treatment. ${ }^{2}$ A recent review of prevalence rate of T2DM and conditions of dysglycaemia in Nigeria revealed impaired glucose tolerance at $10.0 \%$ and impaired fasting glucose at $5.8 \%$ with 4.7 million Nigerians living with T2DM, suggesting $<10.0 \%$ national prevalence rate. ${ }^{2,3}$ Furthermore, demographic, epidemiological and nutritional transitions in Nigeria in the past decades have resulted in increased burden of T2DM coupled with lifestyle changes with major effect of increase in prevalence and impact of T2DM on disability. ${ }^{4}$

Studies have linked T2DM with a high burden of physical limitation and functional disability, ${ }^{5-9}$ putting people living with T2DM at risk of disability with about $25.0 \%$ being more likely to develop disability than those without. ${ }^{6}$ It had been suggested that 6 years after diagnosis of T2DM, $13.6 \%$ of patients will develop disability in one activity of daily living (ADL), while $38.3 \%$ will develop new functional impairment with an average of $1.0 \%$ mean decline in function per year.,

This may imply that activities such as self-care and mobility/ambulation may decline as the disease progresses if untreated. 


\section{Original Article}

Annual work disability rate is reported to be higher among those with T2DM than those without (95 vs. 35 days per year, respectively). ${ }^{10}$

Factors reported to cause increased burden of disability among people with T2DM include older age and metabolic syndrome. Being 50 years and above and metabolic syndrome are said to be predictive of impairment of basic ADL, while lower cognitive function, baseline instrumental ADL problems, insulin therapy and physical inactivity were significant predictors of a future decline in ADL. ${ }^{8}$ Socio-economic status, obesity and exercise have been shown to explain the association between T2DM and disability. ${ }^{11}$ Other factors like gender, racial differences in functional limitations and co-existence of stroke and T2DM are reported to have great impact on disability prevalence. ${ }^{12,13}$ Gender and educational level are reported to affect work disability with the females more at risk. ${ }^{10}$ A study by Virtanen et al. of T2DM employees reported 2 distinct groups characterised by high and low prevalence of co-morbid state: alcohol use, obesity, psychological symptoms and physical inactivity. ${ }^{14}$ The risk of future work disability is predicted by the prevalence.

Differences linking functional limitation or global disability with T2DM have been reported. ${ }^{11}$ This makes accurate estimates of T2DM-associated disability important for their health needs. There is paucity of study on global disability burden in Nigerians with T2DM. Hence, estimating the burden of disability will not only elucidate the magnitude of the problem but also help develop appropriate and targeted screening efforts to reduce societal burden of disability and improve health outcomes for persons with T2DM in Nigeria. This study therefore aimed to determine the prevalence of global disability and its predictors among Nigerians with T2DM.

\section{METHODS}

\section{Design and setting}

This was a cross-sectional study of people with T2DM attending the outpatient clinic of a University Teaching Hospital. The teaching hospital serves Ogun State and receives referrals from other parts of South Western Nigeria. It provides health care services to about 1 million $\mathrm{Ni}$ gerians living in Ogun State, Nigeria. It has an outpatient clinic, the Dame Adebutu Diabetes Care Centre (DADCC), which provides health care service for a wide range of endocrine disorders including T2DM.

\section{Population and sample}

One hundred and sixty-two adults with T2DM, 21 years and older, attending the outpatient clinic of OOUTH and able to grant an interview were consecutively recruited during the study period (March 2016 to May 2017).
Sample size was determined with the assumption of moderate effect size at significant criterion of 0.05 with the formula $N=8 \mathrm{~K}+40$, where $\mathrm{N}$ is the sample size and $\mathrm{K}$ is the number of variables. ${ }^{15}$ To achieve statistically significant prediction using Poisson regression analysis at $\alpha$ $=0.05$ with 10 variables, the calculated sample size is $120:[8 \times 10+40]$.

\section{Assessment of disability}

World Health Organization Disability Assessment Schedule (WHODAS 2.0) short form - a five-point ordinal scale ranging from 1 (none) to 5 (extreme or cannot do it) - was used to assess disability among study participants. World Health Organization Disability Assessment Schedule 2.0 provides a common metric for the impact of any health condition in terms of functioning. Being a generic measure, it provides measures for assessing both physical and mental disability burden of all health conditions whatever their cause. ${ }^{16}$ Its validation had been discussed in another study. ${ }^{16,17}$ For item-based analysis, each item was dichotomised as no disability $(1=$ none $)$ and presence of disability: 2-5 (mild to extreme). The items were re-coded into 0 (none) to 4 (extreme or cannot do it) for both simple sum and item-response theory (IRT) summary score analysis. Summary score of 45 was the cut-off point for overall disability. ${ }^{18}$ Simple sum norm values of 1-4, 5-9 and 10-48 were used to classify survivors as having mild, moderate and severe disability, respectively..$^{19}$ The validity of WHODAS has been reported to be good. ${ }^{16}$ Global disability burden is defined operationally as a general reduction in functioning, that is, body function and structure, personal activities and societal participation.

\section{Covariates}

A structured questionnaire was used to collect information on socio-demographic parameters with self-reported T2DM duration (in month) obtained from the participants. Standard methods were used to assess blood pressure and body mass index (BMI). The most recent laboratory parameters of fasting blood glucose (FBG) and glycosylated haemoglobin (HbAlc) were extracted from patient's medical records.

\section{Statistical analysis}

All data were collated and analysed using Statistical Package for Social Sciences (SPSS) version 16 (SPSS, Chicago, IL).

Continuous and categorical variables were presented as frequency, mean and standard deviation. Significant differences were assessed with chi-squared $\left(\chi^{2}\right)$ test for categorical variables and Student's $t$-test or $F$-test for continuous variables. 
Poisson regression analysis was used to determine association or predictive factors of disability. Level of statistical significance had $p$-values reported as two-sided with predefined $p$-value set at 0.05 .

\section{Ethical consideration}

The Health Research Ethics Committee of Olabisi Onabanjo University Teaching Hospital (HRECOOUTH), Nigeria, approved the study protocol, while all participants gave written informed consent. Clearance number: OOUTH/HREC/40/2016.

\section{RESULTS}

One hundred and sixty-two patients with T2DM (male $74 ; 45.7 \%$ ) with mean (SD) age $60.2(13.0)$ years attending the DADCC of University Teaching Hospital participated in the study. Table 1 shows the prevalence of disability by items. The prevalence of disability was high $(50.6 \%-63.0 \%)$ in 3 items and moderate in nine items ranging between $24.7 \%$ and $46.9 \%$. However, when summary cut-off score (45) was used; only $12.3 \%$ of people with T2DM reported global disability. Adjusted for sex, the pattern of the prevalence was similar as there was no gender difference in the prevalence of disability among the participants (Table 1).

The severity of disability among patients with T2DM attending OOUTH is shown in Figure 1. About a seventh (14.2\%) reported no disability, $25.0 \%$ had mild disability, while $60.5 \%$ reported moderate to severe disability. Although the female participants reported more mild and severe disability than male participants, the difference was not statistically significant. The pattern of disability by socio-demographic and clinical parameters is shown in Table 2. The disability was 22.1 suggesting mild disability based on International Classification of Functioning, Disability and Health (ICF) severity range.
This decreased with increasing level of education and T2DM duration though not statistically significant. Furthermore, there was no gender difference in the pattern of disability among the study participants (Table 2).

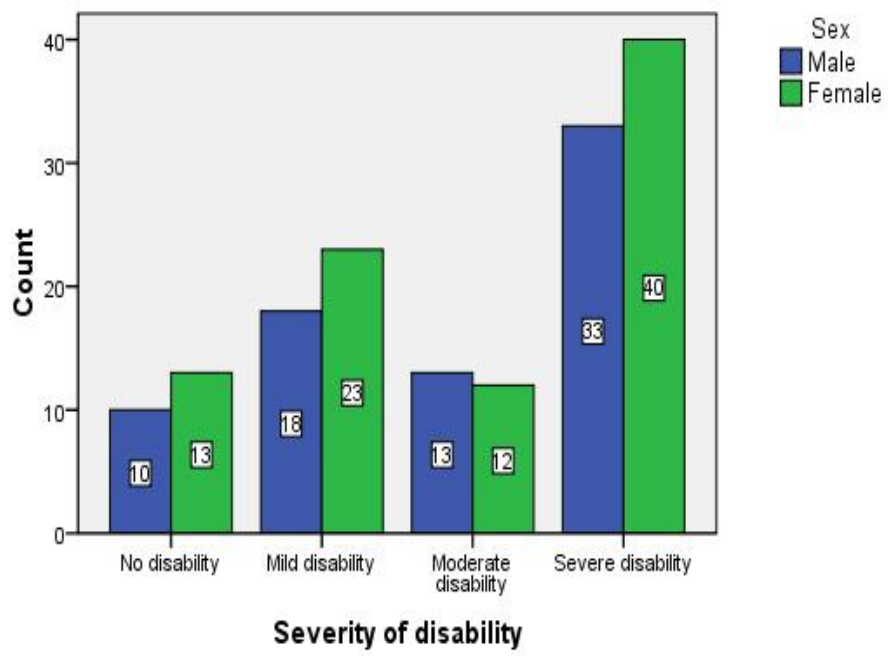

Figure 1 Severity of disability in the patients with T2DM

Poisson regression analysis showed both clinical and socio-demographic variables of FBG, glycosylated haemoglobin (HbA1c), elevated systolic blood pressure (SBP), age, T2DM duration and marital status as significant predictors of disability among people with T2DM (Table 3). With 1-year increase in age and a unit increase in FBG, there was $0.8 \%$ and $0.5 \%$ decrease in disability, respectively, while a unit increase in $\mathrm{HbAlc}$, SBP and 1 month increase in T2DM duration resulted in an estimated $1.062,1.005$ and 1.001 times, respectively, more disability report. The married participants were 1.13 times more likely to be disabled than unmarried.

Table 1 Gender difference in prevalence of disability by items

\begin{tabular}{|c|c|c|c|c|}
\hline \multirow[b]{2}{*}{ Items } & All sample & Male & Female & \multirow[t]{2}{*}{ p-values } \\
\hline & $\mathrm{N}(\%)$ & $\mathrm{N}(\%)$ & $\mathrm{N}(\%)$ & \\
\hline 1. How much difficulty did you have in standing for long periods such as $30 \mathrm{~min}$ ? & $76(46.9)$ & $37(50.0)$ & $39(44.3)$ & 0.47 \\
\hline 2. How much difficulty did you have in taking care of your household responsibilities? & $82(50.6)$ & $41(55.4)$ & 41(46.6) & 0.26 \\
\hline $\begin{array}{l}\text { 3. How much difficulty did you have in learning a new task, for example, learning how } \\
\text { to get to a new place? }\end{array}$ & $56(34.6)$ & $23(31.1)$ & $33(37.5)$ & 0.39 \\
\hline 4. How much of a problem did you have joining in community activities? & $69(42.6)$ & $35(47.3)$ & $34(38.6)$ & 0.27 \\
\hline 5. How much have you been emotionally affected by your health problems? & $102(63.0)$ & $49(66.2)$ & $53(60.2)$ & 0.43 \\
\hline 6. How much difficulty did you have in concentrating on doing something for $10 \mathrm{~min}$ ? & $62(38.3)$ & $28(37.8)$ & $34(38.6)$ & 0.92 \\
\hline $\begin{array}{l}\text { 7. How much difficulty did you have in walking a long distance such as a kilometre [or } \\
\text { equivalent]? }\end{array}$ & $99(61.1)$ & $43(58.1)$ & $56(63.6)$ & 0.47 \\
\hline 8. How much difficulty did you have in washing your whole body? & $42(25.9)$ & $19(25.7)$ & $23(26.1)$ & 0.95 \\
\hline 9. How much difficulty did you have in getting dressed? & $40(24.7)$ & $18(24.3)$ & $22(25.0)$ & 0.92 \\
\hline 10. How much difficulty did you have in dealing with people you do not know? & $46(28.4)$ & $23(31.1)$ & $23(26.1)$ & 0.49 \\
\hline 11. How much difficulty did you have in maintaining a friendship? & $57(35.2)$ & $30(40.5)$ & $27(30.7)$ & 0.19 \\
\hline 12. How much difficulty did you have in your day-to-day work? & $76(46.9)$ & $35(47.3)$ & $41(46.6)$ & 0.93 \\
\hline All items (summary score) & $20(12.3)$ & $9(12.2)$ & $11(12.5)$ & 0.95 \\
\hline
\end{tabular}


Table 2 Pattern of disability by socio-demographic and clinical factors

\begin{tabular}{|c|c|c|c|c|c|}
\hline \multirow[t]{3}{*}{ Variable } & \multirow[t]{3}{*}{$\mathrm{N}$} & \multicolumn{4}{|c|}{ WHODAS 2.0 Summary Score (IRT) } \\
\hline & & Both sex & Male & Female & \\
\hline & & Mean \pm sd & Mean $\pm \mathrm{sd}$ & Mean \pm sd & p-value \\
\hline \multicolumn{6}{|l|}{ Age (years) } \\
\hline$\leq 60$ & 82 & $22.7 \pm 19.3$ & $21.9 \pm 17.9$ & $23.3 \pm 20.5$ & 0.74 \\
\hline \multirow[t]{2}{*}{$>60$} & 80 & $21.4 \pm 18.5$ & $23.0 \pm 20.2$ & $19.9 \pm 16.7$ & 0.45 \\
\hline & & $p=0.65$ & & & \\
\hline \multicolumn{6}{|l|}{ Education } \\
\hline No formal education & 7 & $23.8 \pm 20.9$ & $24.1 \pm 23.6$ & $23.6 \pm 23.4$ & 0.98 \\
\hline \multirow[t]{2}{*}{ Formal education } & 155 & $22.0 \pm 18.8$ & $22.4 \pm 19.0$ & $21.6 \pm 18.8$ & 0.78 \\
\hline & & $p=0.80$ & & & \\
\hline \multicolumn{6}{|l|}{ Marital status } \\
\hline Married & 121 & $22.2 \pm 18.7$ & $21.9 \pm 18.9$ & $22.6 \pm 18.7$ & 0.84 \\
\hline \multirow[t]{2}{*}{ Other } & 41 & $21.5 \pm 19.5$ & $27.1 \pm 21.0$ & $20.2 \pm 19.3$ & 0.38 \\
\hline & & $p=0.84$ & & & \\
\hline \multicolumn{6}{|l|}{ Occupation } \\
\hline Artisan/trading & 68 & $18.7 \pm 16.5$ & $16.8 \pm 16.7$ & $19.6 \pm 16.4$ & 0.52 \\
\hline Professional/teaching & 42 & $23.8 \pm 18.3$ & $23.4 \pm 12.6$ & $24.2 \pm 19.4$ & 0.89 \\
\hline \multirow[t]{2}{*}{ Unemployed/retired } & 52 & $25.1 \pm 21.7$ & $25.9 \pm 21.1$ & $23.9 \pm 23.1$ & 0.75 \\
\hline & & $p=0.14 *$ & & & \\
\hline \multicolumn{6}{|l|}{ Religion } \\
\hline Christian & 115 & $21.7 \pm 19.1$ & $22.9 \pm 18.7$ & $20.8 \pm 19.6$ & 0.56 \\
\hline Muslim & 44 & $22.1 \pm 18.6$ & $21.1 \pm 20.3$ & $23.3 \pm 16.8$ & 0.69 \\
\hline \multirow[t]{2}{*}{ Other } & 3 & $36.1 \pm 2.8$ & 36.1 & $36.1 \pm 3.9$ & 1.00 \\
\hline & & $p=0.57 *$ & & & \\
\hline \multicolumn{6}{|l|}{ Weight status } \\
\hline Underweight & 6 & $28.7 \pm 29.4$ & $29.2 \pm 41.2$ & $28.5 \pm 29.5$ & 0.98 \\
\hline Normal weight & 49 & $23.8 \pm 19.4$ & $22.3 \pm 16.7$ & $25.8 \pm 23.1$ & 0.54 \\
\hline Overweight & 70 & $20.0 \pm 18.4$ & $22.9 \pm 20.0$ & $17.4 \pm 16.7$ & 0.22 \\
\hline \multirow[t]{2}{*}{ Obese } & 37 & $22.7 \pm 17.3$ & $20.3 \pm 21.2$ & $23.6 \pm 16.1$ & 0.62 \\
\hline & & $\mathrm{p}=0.57 *$ & & & \\
\hline \multicolumn{6}{|l|}{ Duration of disability } \\
\hline$\leq 12$ months & 75 & $23.3 \pm 19.1$ & $25.6 \pm 19.3$ & $21.4 \pm 19.0$ & 0.35 \\
\hline \multirow[t]{2}{*}{$>12$ months } & 87 & $21.0 \pm 18.7$ & $20.0 \pm 18.7$ & $22.0 \pm 18.9$ & 0.62 \\
\hline & & $p=0.46$ & & & \\
\hline All sample & 162 & $22.1 \pm 18.9$ & $22.5 \pm 19.1$ & $21.7 \pm 18.8$ & 0.77 \\
\hline
\end{tabular}

Table 3 Poisson Regression Analysis of Disability and Predicting Factors

\begin{tabular}{|c|c|c|c|c|c|}
\hline VARIABLE & B & SEB & IRR & $95 \% \mathrm{CI}(\mathrm{IRR})$ & $p$-value \\
\hline Intercept & 2.568 & 0.311 & 13.045 & $7.097-23.978$ & 0.0001 \\
\hline \multicolumn{6}{|l|}{ Sex } \\
\hline \multicolumn{6}{|l|}{ Female (Reference) } \\
\hline Male & -0.034 & 0.045 & 0.967 & $0.885-1.056$ & 0.46 \\
\hline \multicolumn{6}{|l|}{ Education } \\
\hline \multicolumn{6}{|c|}{ No Formal Education (Reference) } \\
\hline Formal Education & 0.005 & 0.097 & 1.005 & $0.832-1.215$ & 0.96 \\
\hline \multicolumn{6}{|l|}{ Marital Status } \\
\hline \multicolumn{6}{|l|}{ Unmarried (Reference) } \\
\hline Married & 0.121 & 0.054 & 1.129 & $1.015-1.256$ & 0.03 \\
\hline Age & -0.008 & 0.002 & 0.992 & $0.988-0.996$ & 0.0001 \\
\hline Diabetes Duration & 0.001 & 0.001 & 1.001 & $1.000-1.002$ & 0.02 \\
\hline Systolic Blood Pressure & 0.005 & 0.001 & 1.005 & $1.002-1.007$ & 0.001 \\
\hline Diastolic Blood Pressure & 0.002 & 0.002 & 1.002 & $0.998-1.006$ & 0.28 \\
\hline $\mathrm{HbA} 1 \mathrm{c}$ & 0.061 & 0.006 & 1.062 & $1.050-1.075$ & 0.0001 \\
\hline Fasting Blood Glucose & -0.005 & 0.001 & 0.995 & $0.994-0.996$ & 0.0001 \\
\hline Body Mass Index & 0.003 & 0.004 & 1.003 & $0.996-1.010$ & 0.41 \\
\hline
\end{tabular}

\section{DISCUSSION}

Findings from this study suggest that Nigerian with T2DM have mild to moderate burden of global disability greater in the domains of mobility, life activity and participation.
This is in tandem with previous reports linking T2DM with different measures of disability. ${ }^{5-9}$ Those studies reported higher prevalence of disability $(50.0 \%-80.0 \%)$ or risk of developing new disability in terms of functioning after diagnosis of T2DM compared with people 


\section{Original Article}

without T2DM. It is postulated that untreated hyperglycaemia may activate the inflammatory pathway and lead to loss of muscle mass, strength and efficiency, particularly in the lower extremities, which in turn decrease mobility and participation in routine activities and thus aggravate the onset of global disability. ${ }^{7}$

It is therefore appropriate to include measures that reduce global disability in the management of T2DM from onset of diagnosis. This becomes necessary as our finding suggests that $60.5 \%$ of T2DM experienced moderate to severe level of disability. Previous study that used the same measure of disability as ours also reported significant number of T2DM with moderate to severe level of global disability of $77.0 \%{ }^{20}$

Our study reported mild disability among people with T2DM based on ICF severity range. Studies that used generic measure of disability (WHODAS 2.0) are not available for comparison. However, the mild global disability score (22) in this study is lower than the moderate global disability score (44) reported among Nigerian stroke survivors despite using same assessment measure of global disability. ${ }^{18}$ This may suggest that T2DM is associated with less burden of global disability compared with stroke survivors. As our participants are undergoing treatment for glycaemic control, it may also suggest that disability could be avoided or certainly minimised in patients with T2DM if they were to adhere to treatment and health promotion aspects related to their disease. There are studies reporting that people with T2DM who adhered to treatment and lifestyle modification have good clinical outcome. ${ }^{21,22}$

Findings from this study suggest no gender difference in the burden of global disability implying that gender does not predict disability after diagnosis of T2DM. This is similar to that of Sakurai et al., ${ }^{8}$ who reported no gender association with functional disability. Therefore, both sexes should be advised on how to reduce disability after diagnosis of T2DM. Some studies tried to explain the link between disability and T2DM based on gender difference with females having worse disability. ${ }^{11,23}$ Sex differences in burden of disability among people with T2DM as reported by previous studies have not been consistent perhaps because of different methods of assessment used. Thus, variation in burden of disability based on gender was reported in physical performance tests, ADL and instrumental ADL. ${ }^{24}$

Our findings of elevated HbA1c, FBG, SBP, age, T2DM duration and marital status as significant predictors of disability among people with T2DM suggest the multifactorial nature of disability in T2DM and require integration of many factors (including modifiable risks) to determine its severity. These factors (such as older age, longer duration of diabetes and elevated SBP) impacted functioning, lead to more disability being reported among participants and may consequently affect quality of life. Our result that a unit increase in HbAlc and SBP corresponds to $6.2 \%$ and $0.5 \%$ respective increase in global disability suggests that people with T2DM, poor BP and glycaemic control are at high risk of burden of global disability. These observations are in agreement with previous report that T2DM with co-morbid conditions and poor glycaemic control (defined by HbA1c $\geq 7.0 \%$ ) had a higher prevalence of functional disability. ${ }^{7,12}$ Indeed, all patients with T2DM require close monitoring in terms of health education, adjusted lifestyle assistance and lifestyle management to reduce disease burden.

This study suggests an association between duration of DM and burden of global disability. One month increase in DM duration has estimated 1.001 times more disability reported in agreement with previous study which observed an association between duration of DM and functional disability. The reported prevalence of functional disability is said to be increasing by approximately $1.3 \%$ every year for T2DM. ${ }^{7}$ Sequelae of ageing process are likely to add to the burden of global disability among people with T2DM as suggested by our data. About $50.0 \%$ of our study participants are aged ( $>60$ years) and significantly reported reduction in function. There is a probability of loss of autonomy among the aged who may invariably depend on spouse or family members for ADL.

Our study did not show any effect of obesity on the association between T2DM and global disability similar to the report of Assari et al. ${ }^{11}$ though, studies suggest that obesity and overweight may aggravate the link between T2DM and disability. ${ }^{24-26}$ Controlling for BMI explained $38.0 \%$ of the risk of disability in women and $16 \%$ in men. ${ }^{24}$ Attention should therefore be directed at improving modifiable risk factors such as BMI to reduce the burden of global disability. The beneficial impacts of optimising BMI in adults with T2DM on disability later in life are supported by a previous study. ${ }^{27}$ Most risk factors in T2DM are modifiable with appropriate treatment, care and support. Effort should therefore be directed at these to avoid or limit disability among people with T2DM.

This study revealed increased global disability among married participants when compared with unmarried (singles, separated or divorce, and widows or widowers) participants. This is surprising as it is expected that being married will afford better support (economical, emotional, physical and psychological) necessitating further study of effect of marital status on global disability. 
The strength of this study lies in the use of global disability measure and function, WHODAS, to assess disability among individuals with T2DM in this study makes our findings comparable with other studies both on T2DM and other non-communicable diseases. However, WHODAS has been shown to have good psychometric ability in estimating disability among population with ill health. ${ }^{16}$ Our findings being from a tertiary health institution need to be interpreted with caution as it may not be representative of the general population of people with T2DM. Many individuals with T2DM are undiagnosed, walk freely in the community unaware of their health status, while those aware are not clinic or drug compliant, or seek alternative medical treatment. ${ }^{1}$

\section{CONCLUSION}

Nigerians with T2DM exhibit mild to moderate degree and burden of global disability predicted by demographic (age, marital status, disease duration) and clinical (glycaemic and blood pressure control) variables. Interventions are needed to limit future global disability and burden among diabetics above age 50 years.

\section{ACKNOWLEDGEMENT}

We appreciate the efforts of Miss Mubo Olufemi and Miss Oluwadamilola Odueso for editing the manuscript. The manuscript was presented as part at a conference of Association of Clinical and Academic Physiotherapist of Nigeria, Ile-Ife, Osun State. October, 2017.

\section{REFERENCES}

1. International Diabetes Federation (IDF). Diabetes atlas, 7th edn., 2015; International Diabetes Federation, Brussels, viewed 16 August 2017, from http://www.diabetesatlas.org/.

2. Adeloye D, Ige JO, Aderemi AV, Adeleye N, Amoo EO, Auta A, et al. Estimating the prevalence, hospitalisation and mortality from type 2 diabetes mellitus in Nigeria: A systematic review and meta-analysis. $B M J$ Open 2017; 7: e015424.

https://doi.org/10.1136/bmjopen-2016-015424

3. Dahiru T, Aliyu AA, Shehu AU. A review of population-based studies on diabetes mellitus in Nigeria. Sub-Saharan African Journal of Medicine 2016; 3: 59-64. https://doi.org/10.4103/2384-5147.184351

4. Ganu D, Fletcher N, Caleb N.K. Physical disability and functional impairment resulting from type 2 diabetes in sub-Saharan Africa: A systematic review. African Journal of Diabetes Medicine 2016; 24(1): 1014.

5. Dhamoon MS, Moon YP, Paik MC, Sacco RL, Elkind MSV. Diabetes predicts long-term disability in an elderly urban cohort: The Northern Manhattan Study.
Annals of Epidemiology 2014; 24(5): 362-368.e1. https://doi.org/10.1016/j.annepidem.2013.12.013

6. Fishman EI. Incident diabetes and mobility limitations: Reducing bias through risk-set matching. The Journals of Gerontology Series A Biological Sciences and Medical Sciences 2015; 7(7): 860-865. https://doi.org/10.1093/gerona/glu212

7. Godino JG, Appel LJ, Gross AL, Schrack JA, Parrinello CM, Kalyani RR, et al. Diabetes, hyperglycemia, and the burden of functional disability among older adults in a community-based study. Journal of Diabetes 2016; 9: 76-84. https://doi.org/10.1111/17530407.12386

8. Sakurai T, Iimuro S, Sakamaki E, Umegaki H, Araki A, Ohashi Y, et al. Risk factors for a 6-year decline in physical disability and functional limitations among elderly people with type 2 diabetes in the Japanese elderly diabetes intervention trial. Geriatrics \& Gerontology International 2012; 12 (Suppl. 1): 117-126. https://doi.org/10.1111/j.1447-0594.2011.00819.x

9. Wong E, Backholer K, Gearon E, Harding J, FreakPoli R, Stevenson C, et al. Diabetes and risk of physical disability in adults: A systematic review and metaanalysis. The Lancet Diabetes \& Endocrinology 2013; 1:106-114. https://doi.org/10.1016/S22138587(13)70046-9

10. Ervasti J, Virtanen M, Pentti J, Lallukka T, Tinghög P, Kjeldgard L, et al. Work disability before and after diabetes diagnosis: A nationwide population-based register study in Sweden. American Journal of Public Health 2015; 105:e22-e29. https://doi.org/10.2105/AJPH.2015.302646

11. Assari S, Lankarani RM, Lankarani MM. Cross-country differences in the association between diabetes and disability. Journal of Diabetes \& Metabolic Disorders 2014; 13:3. https://doi.org/10.1186/2251-6581-13-3

12. Andrade FCD, Guevara PE, Lebrão ML, Duarte YA. Correlates of the incidence of disability and mortality among older adult Brazilians with and without diabetes mellitus and stroke. BMC Public Health 2012; 12:361. https://doi.org/10.1186/1471-2458-12-361

13. Kalyani RR, Rodriguez DC, Yeh H-C, Golden SH, Thorpe RJ, Jr. Diabetes: Race and functional limitations in older U.S. men and women. Diabetes Research and Clinical Practice 2015; 108(3):390-397. https://doi.org/10.1016/j.diabres.2015.04.003

14. Virtanen M, Vahtera J, Head J, Dray-Spira R, Okuloff A, Tabak AG, et al. Work disability among employees with diabetes: Latent class analysis of risk factors in three prospective cohort studies. PLoS One 2015; 10(11): 0143184. https://doi.org/10.1371/journal.pone.0143184

15. Al-Hassan MA, Al-Akour NA, Aburas MM. Relationship between motivational style and glycaemic control in Jordanian patients with type 2 diabetes mellitus. 


\section{Original Article}

Journal of Diabetes 2016; 9:93-101. https://doi.org/10.1111/1753-0407.12389

16. Ustün TB, Chatterji S, Kostanjsek N, Rehm J, Kennedy C, Epping-Jordan J. Developing the world health organization disability assessment schedule 2.0. Bulletin of the World Health Organization 2010; 88(11):815-823. https://doi.org/10.2471/BLT.09.067231

17. Oyewole OO, Ogunlana MO, Gbiri CAO, Oritogun KS. Prevalence and impact of disability and sexual dysfunction on health related quality of life of Nigerian stroke survivors. Disability and Rehabilitation 2017; 20:2081-2086. https://doi.org/10.1080/09638288.2016.1219395

18. Oyewole OO, Ogunlana MO, Oritogun KS, Gbiri CA. Post-stroke disability and its predictors among Nigerian stroke survivors. Disability and Health Journal 2016; 9(4):616-623. https://doi.org/10.1016/j.dhjo.2016.05.011

19. Andrews G, Kemp A, Sunderland M, Von Korff M, Ustun TB. Normative data for the 12 Item WHO disability assessment schedule 2.0. PLoS One 2009; 4:e8343.

https://doi.org/10.1371/journal.pone.0008343

20. Al-Banna DA, Khuder SA. Disability assessment of diabetic patients in Erbil city. Zanco Journal of Medical Sciences 2015; 19(1):902-909. https://doi.org/10.15218/zjms.2015.0010

21. Lo-Ciganic W-H, Donohue JM, Jones BL, Perera S, Thorpe JM, Thorpe CT, et al. Trajectories of diabetes medication adherence and hospitalization risk: A retrospective cohort study in a large state Medicaid Program. Journal of General Internal Medicine 2016; 31(9):1052-1060.

https://doi.org/10.1007/s11606-016-3747-6
22. Musenge EM, Michelo C, Mudenda B, Manankov A. Glycaemic control and associated self-management behaviours in diabetic outpatients: A hospital based observation study in Lusaka, Zambia. Journal of Diabetes Research 2016, Article ID 7934654, 1-9. https://doi.org/10.1155/2016/7934654

23. Schmitz N, Nitka D, Gariepy G, Malla A, Wang J, Boyer R, et al. Association between neighbourhoodlevel deprivation and disability in a community sample of people with diabetes. Diabetes Care 2009; 32:1998-2004. https://doi.org/10.2337/dc09-0838

24. Maggi S, Noale M, Gallina P, Marzari C, Bianchi D, Limongi $\mathrm{F}$, et al. Physical disability among older Italians with diabetes: The ILSA study. Diabetologia 2004; 47:1957-1962. https://doi.org/10.1007/s00125004-1555-8

25. Curtis B, Hayes R, Fehnel S, Zografos L. Assessing the effect of weight and weight loss in obese persons with type 2 diabetes. Diabetes, Metabolic Syndrome and Obesity 2008; 1:13-23. https://doi.org/10.2147/DMSO.S4237

26. Hayes RP, Nelson DR, Meldah ML, Curtis BH. Ability to perform daily physical activities in individuals with type 2 diabetes and moderate obesity: A preliminary validation of the impact of weight on activities of daily living questionnaire. Diabetes Technology \& Therapeutics 2011; 13(7):705-712. https://doi.org/10.1089/dia.2011.0027

27. Chiu C-J, Wray LA, Lu F-H, Beverly EA. BMI change patterns and disability development of middle-aged adults with diabetes: A dual trajectory modeling approach. Journal of General Internal Medicine 2013; 28(9):1150-1156.

https://doi.org/10.1007/s11606-013-2399-z

Copyright (C) The Author(s). This is an Open Access article under the CC BY license. 